Dossier Anthropology on Latin America and the Caribbean today:

New Theoretical and Methodological Challenges

\title{
¿Qué será la interculturalidad?
}

\author{
Néstor García Canclini' \\ 'Universidad Autónoma Metropolitana, México
}

\section{Resumen}

A los antropólogos se nos piden políticas para gestionar la multiculturalidad. Sin embargo, los conflictos interculturales aumentados por las migraciones masivas, la expansión mundial de las industrias comunicacionales, la mezcla de formas productivas y consumos locales, nacionales y globales cambiaron las condiciones de convivencia entre etnias, naciones, géneros y generaciones. Este artículo contribuye a reimaginar las tareas actuales de la antropología revisar cómo trataron los malentendidos interculturales antropólogos y sociólogos de varios países: Marc Abélès, Roberto da Matta, Gustavo Lins Ribeiro, Claudio Lomnitz, Guillermo O’Donnell, Renato Ortiz, Rossana Reguillo y Ana Rosas Mantecón, así como en los estudios recientes sobre jóvenes, tecnologías e intercambios académicos. El autor analiza el papel de las discrepancias en la interacción entre culturas en un tiempo en el que ganan fuerza los fundamentalismos identitarios.

Palabras clave: antropología; interculturalidad; multiculturalismo; fundamentalismos de identidad. 


\title{
What will interculturality be?
}

\begin{abstract}
We anthropologists are often asked to design policies in order to manage multiculturalism. But intercultural conflicts magnified by massive migrations, the global expansion of the communication industries and the merging of local, national and global production and consumption patterns have changed the conditions of coexistence between ethnic groups, nations, genders and generations. This article contributes to reimagining the current tasks of anthropology reviewing how anthropologists and sociologists from various countries dealt with intercultural misunderstandings, such as Marc Abélès, Roberto da Matta, Gustavo Lins Ribeiro, Claudio Lomnitz, Guillermo O'Donnell, Renato Ortiz, Rossana Reguillo, Ana Rosas Mantecón and recent studies on youth, technologies and academic exchanges. The author analyses the discrepancies between cultures that interact in a time when identitarian fundamentalisms are gaining strength.
\end{abstract}

Keywords: anthropology; interculturality; multiculturalism; identity fundamentalisms.

\section{O que será a interculturalidade?}

\section{Resumo}

Nós antropólogos somos solicitados a definir políticas para gerenciar o multiculturalismo. No entanto, os conflitos interculturais incrementados por migrações em massa, a expansão global das indústrias de comunicação, a mistura de formas produtivas e consumo local, nacional e global mudaram as condições de convivência entre etnias, nações, gêneros e gerações. Esse artigo, contribui para reimaginar as tarefas atuais da antropologia ao revisar como antropólogos e sociólogos de vários países lidaram com mal-entendidos interculturais: Marc Abélès, Roberto da Matta, Gustavo Lins Ribeiro, Claudio Lomnitz, Guillermo O’Donnell, Renato Ortiz, Rossana Reguillo e Ana Rosas Mantecón, bem como estudos recentes sobre juventude, tecnologias e intercâmbios acadêmicos. $O$ autor analisa o papel das discrepâncias na interação entre culturas em um momento em que os fundamentalismos identitários ganham força.

Palavras-chave: antropologia; interculturalidade; multiculturalismo; fundamentalismos identitários. 


\title{
¿Qué será la interculturalidad?
}

\author{
Néstor García Canclini
}

\section{Introducción}

Una definición de la antropología que no recuerdo haber leído ni escuchado: los antropólogos son gente que se apasiona estudiando a otros con los que no está de acuerdo. La fascinación -con una tribu, un movimiento social racista, unos mitos en los que no se cree- me hace preguntar si hay algo propio de este modo de hacer ciencia social llamada antropología que nos haga elegir lo que no compartimos. Hoy los ejemplos proliferan en la bibliografía: laicos que investigan a neoevangélicos y fanáticos católicos de derecha, defensores de derechos humanos que hacen tesis sobre linchamientos y feminicidios.

Hemos leído que los antropólogos se interesan por otras sociedades debido a que rechazan la propia, o se dedican a sectores discriminados de la suya para pensar lo que quisieran cambiar, sin dejarse confundir por lo que su educación les inculcó como natural. Puede ser, en algunos casos. Pero más allá de la intención crítica -o junto con ella- hay atracciones que provienen de rasgos específicos de esa cultura y por eso no elegimos tantas otras con las que también discrepamos.

Se me ocurrió esta línea exploratoria cuando me invitaron a participar en un homenaje a Manuel Gutiérrez Estévez. Cuando nos escribimos o nos encontramos él me da sus textos sobre los indígenas en los Andes y lo que cuentan los pobladores de Yucatán sobre lo que sucedió hace siglos; yo le entrego un artículo que busca comprender la diferencia y la desigualdad en las conexiones virtuales. Él me ha invitado a Trujillo, donde reunió varios años a expertos en culturas aborígenes de América, y aceptó que yo llevara un texto sobre negociación de las identidades en la globalizada postpolítica. Manuel me contó en un correo que acababa de presentar en Amberes su estudio sobre la sentimentalidad en la poesía indígena y que sigue dando vueltas en torno a las devociones del catolicismo popular en Extremadura; le contesté que podríamos vernos en mi próximo viaje a España y me encantaría que visitáramos la feria de arte contemporáneo madrileña. Fuimos juntos (García Canclini, 2018a).

Alejadas aficiones profesionales pueden dar sabor a la amistad, las divergencias epistémicas se vuelven casi insignificantes y entre-tienen lo que se conversa, más aún cuando a la vez se descubren arroces y pastas. Esas charlas pueden incluir hallazgos gastronómicos en los trabajos de campo, relatos sobre las discrepancias en la propia universidad, las visitadas o en los congresos académicos y en los de parlamentarios de nuestras naciones. De otras diferencias quiero hablar aquí.

\section{De la multi a la interculturalidad}

Deseo tratar la productividad y las decepciones de la interculturalidad en algunas interacciones de los países latinoamericanos e iberoamericanos. Suele mencionarse la diversidad de lugares y culturas que dificulta hacerse cargo de Nuestra América, nuestra Patria Grande, pero poco se intenta comprender las integraciones en minúscula. Se viene haciendo en los dramas de los migrantes, los exilios y el racismo cotidiano. Comprobamos que la antropología avanza al analizar lo que nos pone en desacuerdo, cuando los estilos de vida de los otros desafían orgullos nacionales o el confort de las rutinas. Lo he notado en reuniones de los organismos 
internacionales, me he preguntado qué podríamos decir los antropólogos, quizá distinto de otros científicos sociales convocados a esas asambleas - sociólogos, políticos y economistas-, más propensos a construir alianzas o transacciones.

A los antropólogos nos llaman a veces cuando se intenta administrar los conflictos interétnicos, regionales y urbanos, como especialistas en escalas microsociales y sobre todo de carácter cultural. ¿Qué se nos pide? Políticas de multiculturalidad: gestionar las fronteras más amablemente que los muros, organizar a las etnias o los migrantes en barrios distintos, moderar con cupos o cuotas los efectos desigualadores de las diferencias. Pocas veces para elaborar políticas de justicia y gobernanza; más bien, como dicen las consultoras, para "controlar los daños". Y efectivamente, un giro de la práctica profesional en las décadas recientes es que ofrecen empleos no solo los Estados; también ONG interesadas en políticas públicas y empresas privadas que incorporan lo cualitativo al saber provisto por las encuestas.

La interculturalidad agresiva del siglo XXI incita, sin embargo, a preferir este término para reconocer los conflictos, la coexistencia ineludible que se vuelve insoportable, los deseos de alejar a los diferentes y quitarles derechos. Las migraciones masivas y las industrias evidencian que los desentendimientos y disputas se multiplican internacional e intercontinentalmente. Desde que la pandemia impuso confinamientos y las pérdidas económicas acentúan la aprensión hacia lo distinto, las antropologías de lo local y nacional se quedan cortas.

No faltan, desde el siglo pasado, antropólogos que trascienden las comunidades étnicas o urbanas para internarse en objetos de estudio de tamaño transnacional. Marc Abélès lo hizo en la Comunidad Europea y su trabajo de campo entre miles de consultores, abogados y expertos agrícolas, financieros y jurídicos, así como con embajadores, ministros y sindicatos, le permitió descubrir que, debajo de las deliberaciones parlamentarias, había cabildeos ("lobbysmo") y lo que nombraban política escondía negociaciones poco democráticas entre cúpulas empresariales. Vimos con el tiempo cuánto cuesta traducir esos arreglos de "libre" comercio a fin de volverlos comprensibles, y creibles, para los ciudadanos. Ocurre aun en un régimen institucional, el de la Unión Europea, que extiende los acuerdos mercantiles y dedica fondos a construir "un espacio audiovisual europeo", programas como Media, Euroimages, intercambios educativos de Erasmus y hasta pasaportes compartidos, moneda única, himno y bandera para impulsar la identidad europea con un repertorio de símbolos.

Abélès volvió a mostrar la fecundidad del trabajo antropológico en amplia escala cuando estudió la Organización Mundial del Comercio. Halló que las tendencias homogeneizadoras se desestabilizan al entrar en tensión con los desequilibrios de la economía de mercado: la etnografía que realizó durante tres años con investigadores de Argentina, Camerún, Canadá, China, Corea, Estados Unidos y Francia revela la complejidad intercultural de su diplomacia comercial, las divergencias persistentes en medio de juegos de transparencia y secreto. La etnografía hizo visible el reverso de la escenografía (Abélès y otros, 2011).

Un antropólogo brasileño, Gustavo Lins Ribeiro, demostró en su estudio sobre el Banco Mundial que ese organismo, pese a emplear a personas de más de ciento treinta países, limita su cosmopolitismo mediante el poder uniformador de una lengua (el inglés), administra gerencialmente la diversidad bajo una sola ideología del desarrollo y elimina las experiencias de otredad al vincularse sólo con las elites políticas y administrativas locales (Lins Ribeiro, 2008).

Cuando en 1999 terminaba de escribir el libro La globalización imaginada (2001), en el que incluí referencias a la investigación de Abélès (1996) sobre la Comunidad Europea y argumentaba con estudios sobre las industrias editorial, del cine y las artes visuales que la mundialización era asimétrica y a la vez se despedazaba en países de América Latina, descubrí dos urgencias: a) que debía problematizar de dónde hablaba sobre los procesos globalizadores: un argentino que vive, enseña e investiga desde México; b) que debía nacionalizarme mexicano para sostener legalmente mi pretensión de decir algo sobre este país, aunque sabía que las prevenciones suscitadas por mi acento y las escuchadas de mexicanos ante artistas que habían pintado a sus indígenas 
y fotografiado la vida cotidiana, o historiadores y antropólogos europeos y estadunidenses que destinaron décadas a estudiar la revolución, no desaparecerían con ese trámite. Lo aprendido en la antropología, además, me hacía sorprenderme que al acto de recibir la nacionalidad se lo designara oficialmente como "naturalización".

De manera que decidí escribir un apéndice titulado "Hacia una antropología de los malentendidos". Comienza este texto con una distinción entre hacer historia o antropología de México o hacer arte mexicano. Recuerdo el argumento, porque tal vez ayude a discutir sobre interculturalidad y trabajo científico. Y también para revisar conclusiones que hoy veo de otro modo.

Pensaba entonces que el consenso internacional en las ciencias sociales podía construirse y justificarse en un campo de relativa objetividad. Pertenecer a una nación o sumergirse en su historia y su cultura cotidianas puede ser útil en el momento del descubrimiento, para formular hipótesis, pero en seguida el investigador debe cuestionar las certezas del sentido común, someter sus hipótesis a pruebas sin pedir ningún privilegio metodológico para las certezas acumuladas por haber nacido y pasado su infancia familiarizándose con lo que una nación, una etnia o una región consideran su identidad. Dado que esa inmersión en lo identitario puede dar tantas ventajas como anteojos, es posible -como de hecho ocurre- que las historias de la revolución y la modernización mexicanas escritas por Alan Knight y François Xavier Guerra sean tan pertinentes y tan discutibles como las de los historiadores de El Colegio de México.

Si existen justificadas objeciones a los estudios antropológicos de Robert Redfield y de Oscar Lewis no es porque su condición de extranjeros les impidió comprender aspectos peculiares de la vida mexicana, sino por razones análogas a las que nos hacen discrepar de los trabajos de Manuel Gamio y Gonzalo Aguirre Beltrán: los presupuestos teóricos con que unos y otros guiaron sus observaciones de campo después se mostraron poco consistentes, o ya no sirven para descifrar nuevos procesos socioculturales que ellos no pudieron prever.

Explicaba en aquel texto por qué me parecía parcialmente legítimo hablar de una literatura mexicana a la que pertenecen, por ejemplo, Octavio Paz, Carlos Fuentes y José Emilio Pacheco; o de un cine mexicano formado, entre otros, por Fernando de Fuentes, el Indio Fernández y Arturo Ripstein, pero en los que no situaríamos Bajo el volcán de Malcom Lowry ni las películas filmadas por Einsenstein en México. En cambio, no veo pertinente hablar de una antropología mexicana como si existiera un modo nacional de hacer ciencia, sino más bien de una antropología de o sobre México.

Esa distinción deja problemas sin resolver. Uno es qué hacer con vastas partes de las obras de Paz, Fuentes y Pacheco que pueden ser comprendidas sin haber vivido nunca en México, porque dialogan no sólo con este país sino con el arte y la literatura de otros, y lo que cabe llamar la condición contemporánea. Una dificultad más: si bien es razonable no convertir a Einsenstein en un realizador mexicano, sería difícil excluir del cine mexicano las películas que el español Luis Buñuel filmó durante su estadía en este país.

Ahora quiero detenerme en un ejercicio que incluí en aquel apéndice para asumir la posición intercultural, pero situada, desde dónde hacía mis estudios e interpretaciones. Ya que casi no encontré en aquel momento investigaciones sobre la interculturalidad entre latinoamericanos, menos aún sobre organismos internacionales dedicados a políticas culturales, el recurso Abelès no existía. Muy escasas encuestas o trabajos etnográficos entre países de la región permitían avanzar, porque las antropologías latinoamericanas estaban especializadas en el autoconocimiento nacional.

Se me ocurrió ampliar una técnica hallada en un estudio de Roberto da Matta (1980). Partía de una frase -"você sabe com quem está falando"-, que el antropólogo brasileño valoraba como parte de un ritual, en el que se marca una asimetría, la separación radical y autoritaria entre dos posiciones sociales. Cuando se enuncia esa fórmula, se está negando el carácter "cordial" que la sociedad brasileña suele atribuirse a sí misma y exhibir ante los otros. A los demás se les enseña el fútbol, la samba, se les habla de las playas, pero no se los coloca ante esta pregunta que es el correlato, según este autor, del "cada uno en su lugar". La frase se usa hacia dentro para restablecer, en una sociedad jerárquica, una superioridad desafiada. 
Se evidencia, así, la coexistencia de dos concepciones de la realidad nacional: una es la visión del mundo como lugar de integración y cordialidad; la otra es la visión del orden social centrado en categorías exclusivas, colocadas en una escala de respetos y diferencias.

Cuatro años después, en 1984, Guillermo O’Donnell buscó una frase comparable en la cultura argentina: “¿Y a mí qué me importa?”. Tiene una segunda versión más enfática: “¿Y a mí qué mierda me importa?”. Se emplea, decía O'Donnell, de modo semejante a Brasil, cuando alguien se siente en una situación violenta por una "intolerable igualdad" y trata de re-jerarquizar el vínculo. "Pero, en contraste con los cariocas de Da Matta, el interlocutor porteño es, precisamente, un interlocutor: encuentra frente a sí a otro hablante. Éste, sin ceremonias, suele mandar, redonda y explícitamente, a la mierda al otro y, junto con él, a la jerarquía social sobre la cual quiso montarse". En realidad, afirma O’Donnell, el interpelado no niega ni cancela la jerarquía: la ratifica, aunque de la forma más irritante posible para el superior. Incluía un conjunto de interacciones en las que esta violencia recíproca organiza las relaciones en Argentina: cuando se trata de entrar desde una calle lateral, durante las horas densas del tránsito, a una avenida, en Estados Unidos se va pasando en el orden en que cada uno llegó a la esquina; en Río de Janeiro es más problemático, pero acaba resolviéndose como "favor", agradecido con el gesto erecto del pulgar por el beneficiario; "en Buenos Aires somos aparentemente iguales: es regla que si no hay policía a la vista (o presumiblemente escondido) cada uno debe pasar primero. Por lo tanto, parte del asunto es impedir que pase el otro. [ ...] La forma de hacerlo, teóricamente ilegal pero universalmente practicada, es 'meter la trompa' (o 'meter la punta'). Resultado, los autos que avanzan hasta rozarse". [ ...] "La consecuencia de esto es, por supuesto, una monumental ineficiencia, peleas, insultos y, no pocas veces, el gesto sobrador' ... cuando no pulgar o índice cerrados en evocativo círculo, del que consiguió meterle la trompa al otro y lo deja, frenando y con rabia (parece título de tango), a pocos milímetros del auto que se desliza victoriosamente." O'Donnell vincula estos comportamientos cotidianos con la violencia de la represión militar -que no tengo ahora tiempo de resumir-y eso lo lleva a interpretar que la sociedad argentina tal vez sea más igualitaria que la brasileña pero igualmente autoritaria y violenta. Esas conductas corresponden a una "sociedad individualista, llena de confrontaciones que no resuelven nada, pero activan la furia de los más poderosos". Los minidramas de los enfrentamientos individuales despliegan una apariencia de igualdad que no deja de ratificar las diferencias existentes, de forma que además siembra resentimientos y ocluye posibilidades cooperativas" (O'Donnell, 1984: 20-21).

Quise completar esa comprensión de los desentendimientos entre latinoamericanos, indagando si la descripción de O’Donnell contribuía a comprender las dificultades de muchos argentinos para adaptarse a la sociedad mexicana. Una frase que nos había irritado a varios -a mí en uno de los lugares menos apropiado, la Secretaría de Gobernación, cuando se atoraban los trámites para conseguir la visa- era: "el que se enoja, pierde". Para descentrarme, busqué otras, le pedí a dos grupos de alumnos de posgrado que propusieran las que juzgaban representativas de la cultura mexicana, infiltré la mía y les pedí que eligieran una, escribieran una página explicando por qué y contaran alguna situación en que la habían usado u oído. Varios extranjeros y dos mexicanos de origen norteño escogieron la que destina a perder a quien se enoja.

Resumo que, según mi interpretación de aquel momento, sería una frase que los mexicanos usan internamente, como en Brasil, en situaciones donde alguien desafía el orden y las jerarquías. Se aplica -o se nos explica- a los extranjeros cuando nos impacientamos sin hacernos cargo de esas jerarquías, apurados por resolver un trámite o un conflicto sin guardar los modos locales. Es posible interpretar literalmente esta frase como síntoma de relaciones que prohíben enojarse y promueven la resignación, al menos para quienes ocupan posiciones subordinadas. No faltan análisis de autores mexicanos, como los de Octavio Paz y Roger Bartra, que avalan esta línea interpretativa sobre la sociedad en general, aunque no se refieran a esta frase. 
Me parece conveniente, en la dirección de los estudios referidos sobre Brasil y Argentina, entender esta fórmula como parte de una organización ritual del poder y las jerarquías sociales que, según escribe Claudio Lomnitz, van asociadas a "utilizaciones tácticas de la ambigüedad" (Lomnitz,1992: 99).

Me sugiere una interpretación distinta, quizá complementaria, la antropóloga mexicana Ana Rosas Mantecón. La idea de el que se enoja pierde no sería una forma de resignación, sino más bien de pasar a otro procedimiento: la negociación. No se trataría necesariamente de renuncia ni sometimiento, sino de entonación, el estilo, con que se quiere buscar el arreglo.

Cabe aclarar que esta descripción de la cultura mexicana no es extensible a todo el país. Algunos mexicanos nacidos en Veracruz o en el norte de México me han hecho notar que su carácter más expresivo, su modo más directo de relacionarse y expresar los afectos, no queda bien representado por esa caracterización que juzgan más pertinente para los habitantes de la meseta central. Tal vez la centralización de la nación ha sobredeterminado la imagen global de "lo mexicano", de modo equivalente a como los rasgos de los porteños son atribuidos a pobladores de toda la Argentina. Como en otras sociedades, la cómoda formación de estereotipos nacionales no deja distinguir las diferencias de cada región.

Si bien el carácter clave o no de esta frase debería ser demostrado por una investigación más extensa, me interesa señalar el contraste con el tipo de cultura característico de zonas de la sociedad argentina y que los nativos quisiéramos reencontrar en el extranjero. La oposición entre las fórmulas identificadas como representativas de Argentina y México corresponde a las diferencias entre una sociedad donde la expresividad interpersonal es más directa, suele burlarse de las instituciones y de las fórmulas institucionalizadas de interacción, es poco ceremonial, como anota O’Donnell, y otra sociedad, la mexicana, donde los conflictos y las distancias se hallan intensamente ritualizados, las instituciones duran más y, pensaba hace veinte años, existen potentes tradiciones comunitarias históricas que harían buscar prioritariamente la reproducción pacífica del conjunto de la sociedad. Suponía en esos tiempos que los argentinos podíamos aprender a vivir en México si prestábamos más atención a los rituales y a las formas en que los sentimientos se integraban en el sentido comunitario o social.

Conté hace poco esta historia comparativa a dos grupos de alumnos de antropología. Una estudiante dijo de inmediato: "pero si todos estamos enojados". Varios asintieron. Pregunté sus razones. Aunque ya vivíamos las frustraciones impuestas por la pandemia, casi no aludieron a eso. Hicieron énfasis en lo que habíamos descubierto desde hace más de una década en estudios sobre "jóvenes creativos" o "emprendedores" en México: la precariedad laboral crónica, lo que ya ni se puede esperar de las instituciones (un poco más de las redes), la desaparición de la idea de carrera y el trabajo por proyectos (inestables y discontinuos), la apertura del sentido de nación a la búsqueda de opciones fuera del país como migrantes. ¿No vivimos en los últimos años expresiones frecuentes de indignación, marchas, protestas de jóvenes maltratados en actividades informales, 0 empujados a lo ilegal? Varios investigadores de la condición juvenil advertimos que los modos de pertenencia e identificación obligan, sin que desaparezca el referente nación (en minúsculas), a destacar como objeto de estudio las palabras frecuentes en el lenguaje de nuevas generaciones: escenas, circuitos, plataformas (Feixa, 2014; Reguillo, 2017).

De nuevo, este desplazamiento de los referentes identificatorios no es generalizable a toda la población. Más aún: aleja a los jóvenes de los códigos de los adultos, no solo por la asimilación más fluida de las nuevas generaciones a las tecnologías y lo trasnacional. Otras maneras de organizarse, con horizontes internacionales, exigen ampliar el sentido de lo intercultural a lo inter-etario. Las divergencias socioculturales entre generaciones pueden ser tan significativas como la interculturalidad entre naciones y etnias. 


\section{Una antropología politeísta}

Las nuevas modalidades de lo inter remiten a lo trans: lo interétnico en las migraciones tiene que ver con la reorganización transnacional de la economía y los servicios; lo interetario implica que los jóvenes se distancian de los hábitos culturales de sus mayores locales al insertarse en lo transmedial y lo transnacional. Esta reconfiguración de los objetos de estudio antropológicos viene produciéndose desde hace décadas. Veo un aporte inaugural en el libro de Renato Ortiz A moderna tradição brasileira, publicado en 1988.

Ortiz fue de los primeros investigadores latinoamericanos en captar que las naciones y los vínculos entre ellas se están rehaciendo desde mediados del siglo XX por la expansión de las comunicaciones mediáticas. Decía que, a diferencia de quienes critican la modernidad desde las tradiciones nacionales, como Gilberto Freyre, había que cuestionarla desde las industrias culturales y "la cultura de masa". Esa fue la primera novedad: un antropólogo que no se atrinchera en el folclor o en las formas comunitarias históricas. Si lo popular es ahora organizado industrialmente y a escala transnacional, necesitamos analizarlo en relación con la televisión y el cine, con el star system.

Segunda innovación: entre dos rasgos clásicos de la práctica antropológica -pensar desde las tradiciones y situarse en la perspectiva de vida de los actores- Ortiz prioriza la segunda. En vez de descifrar lo masivo y su internacionalización como amenazas a las culturas locales y nacionales, según lo que las élites habían consagrado, quiso registrar dóndey qué consumen los sectores populares, qué usan y gustan. No para idealizarlo, sino para interrogarlo fuera de los patrones establecidos por la escuela y la cultura letrada. Vinculó el trabajo etnográfico con la sociología de la cultura para atender los condicionamientos estructurales de las prácticas simbólicas y a los diversos modos de reapropiación y uso de los productos; repensar, entonces, la antropología no como custodia de lo auténtico o lo "propio", sino en el proceso nacional y transnacional-mediático de sus cambios.

Renato Ortiz realizó trabajos de campo en estas intersecciones, desde A Morte Branca do Feiticeiro Negro hasta análisis comparativos sobre las telenovelas en Brasil, México y Cuba, y su recepción dispar en cada país. Mostró, con datos duros, que la industrialización de la cultura administrada por grandes conglomerados estaba transformando los vínculos entre creación artística, hábitos de consumo y lugares de acceso a bienes culturales: en los ochenta se generalizó el uso de casetes en los automóviles, el acceso a la televisión y luego a las videocaseteras. Hubo una "mudança da mentalidade empresarial”, una reconversión incluso de la cultura de los empresarios no ligados directamente a la producción de bienes simbólicos. También observó que esta producción industrializada y transnacional desplazó el eje de las preocupaciones sobre las identidades y la configuración del sentido social: la definición de la nacionalidad brasileña, que Silvio Romero o Teófilo Braga discernían a partir del "cruzamento do negro, do branco e do indio" (Ortiz, 1988: 169), y oponían a lo extranjero, se reformuló en escenas internacionales.

Conclusión teórica: en los años setenta y ochenta, se transitó de la defensa de lo nacional-popular a la exportación de lo internacional-popular. La radio, la televisión y la circulación de libros nutridos predominantemente por contenidos extranjeros, se modificó al crecer la producción de telenovelas y películas brasileñas. Brasil se convirtió en el séptimo mercado mundial de televisión y publicidad, sexto en discos, lo cual correspondía al hecho de que el país pasara a ser la octava economía mundial. Esta reubicación implicó modificar los contenidos y adecuarlos a las normas de calidad de los "mass media internacional" (Ortiz, 1988: 205).

1 Retomo aquí algunas referencias a la obra de Renato Ortiz que desarrollé en el artículo “La cultura internacional-popular en el siglo XXI” (2018b). 
¿Qué le sucede al antropólogo que realiza este giro en su trabajo? Dice Renato: "não falo como brasileiro, ou latino-americano, embora saiba que no fundo é impossível, e indesejável, liberar-me totalmente desta condição. Mas como 'cidadão mundial'. Alguém que, situando-se num determinado lugar do planeta, resolveu enxergá-lo de todos os pontos (mesmo tendo consciência de que meu esforço élimitado). Não quero com isso desvalorizar uma visão territorializada. Mas creio que a reflexão deve alçar vôo, desprendendo o pensamento do peso de nossa herança intelectual. Talvez desta forma possamos compreender a problemática nacional com outros olhos" (Ortiz, 1997: 9).

Reubicar la antropología en la formación de una cultura internacional-popular (más allá de la nominación gramsciana -"nacional-popular", tan empleada en aquel tiempo) requería investigar a la vez los dispositivos técnicos, sus usos variables y las ramas de la industria cultural. "Filmes, programas de televisão, música, conversas telefônicas não se misturavam. Com o advento da telemática, os meios de comunicação se articulam a um único fluxo. Com a microelectrônica, a codificação e a transmissão das mensagens adquirem um caráter de transversalidade. Som, imagem e texto são convertidos em bits e reconvertidos em seus respectivos conteúdos quando chegam a seus destinos. Atividades paralelas tornam-se conexas. A televisão já não está simplesmente conectada aos diversos canais (grandes redes, TV a cabo, parabólica), mas a tela faz o papel de visor, integrando os cassetes, os jogos electrónicos e o computador" (Ortiz, 1997: 63).

La globalización de formas productivas, hábitos de consumo y una memoria colectiva internacionalpopular iba creando identificadores compartidos en muchos países: Hollywood, Coca Cola, actores y actrices de cinematografías de varios continentes devenían símbolos mundiales. ¿Qué tipo de universalismo configuraban las transnacionales? En parte, un poco homogeneizado. Pero no totalmente. Las fidelidades nacionales no desaparecían, podían convivir con dioses variados, elegidos según la lógica expansiva de la mercadotecnia y por las alianzas que lograban con simbolizaciones nacionales.

Ortiz recurrió a los repertorios heteróclitos brasileños para decir: "A modernidade é pluri-religiosa, abrindo espaço para que as mais diversas concepções de mundo, inclusive ideários políticos conflitantes, coabitem entre si. Eu diría que a globalização acentua a erosão do monolitismo simbólico" (Ortiz, 1994: 135). El autor cita una frase de Michael Porter: "homogeneização e segmentação não são incompatíveis" [...] "A ironia é que através da segmentação pede-se criar universalidades" (Ortiz, 1994: 171).

Tantas culturas fusionadas en Brasil ofrecen vías para repensar el debilitamiento de las lealtades nacionales en medio del despliegue de otros sistemas simbólicos difundidos, impuestos o reelaborados transnacionalmente. Según Ortiz, la sociedad mundializada se ha vuelto politeísta. "Os cultos, as seitas, as crenças se preservam, mas sem a capacidade de articular organicamente o todo das relações sociais" (Ortiz, 1994: 218).

Sí y no. Brasil, México y otros países latinoamericanos evidencian en su descomposición política de los últimos años, en la agudización de confrontaciones interétnicas, religiosas, de género, entre generaciones, el difícil tránsito del reconocimiento de la pluralidad cultural (logrado en varias Constituciones latinoamericanas desde los años 9o) a formas nuevas de institucionalidad que vuelvan operativa la convivencia de los diferentes, garanticen los derechos y fomenten la creatividad convergente. Dos ejemplos, entre muchos: a) el saboteo gubernamental y de las élites "blancas" a los Acuerdos de San Andrés, resultado de negociaciones luego de la insurgencia zapatista, que impidió consolidar derechos reivindicados por los pueblos originarios; b) la exasperación reciente del racismo en países como Colombia y Perú, donde los sectores hegemónicos erosionan los acuerdos de paz, las comisiones de la verdad y descalifican una participación equitativa de los grupos indígenas en las políticas nacionales.

En contraste, me refiero brevemente a una investigación aún en curso sobre la desinstitucionalización y reinstitucionalización de la cultura durante la pandemia en Brasil y México, que estamos desarrollando en la Cátedra Olavo Setubal del Instituto de Estudios Avanzados de la Universidad de São Paulo. Como en tantas otras sociedades, la emergencia sanitaria obligó a cerrar museos, cines, centros culturales. 
La situación se volvió aún más crítica por el desconocimiento del peligro y la falta de atención oportuna del gobierno de Bolsonaro. Las actividades culturales canceladas dejaron sin trabajo ni ingresos a más de 800,000 artistas y gestores. Los fondos públicos, que ya venían estrechándose, cayeron en el desamparo. Sin embargo, la tradición de consejos ciudadanos de gestión participativa en Brasil, incentivada con recursos económicos, equipos musicales, tecnologías digitales y apoyos organizativos desde el primer periodo de Gilberto Gil como ministro de cultura (1994), por ejemplo, a través de los Puntos de Cultura, construyó una base fuerte de organización desde las comunidades. Además de crear nuevas estructuras y equipamientos culturales, se buscó fortalecer iniciativas ya existentes en los municipios e integrarlos en un Programa de Cultura Viva, "que también incluye propuestas en Cultura Digital, diálogo de saberes ancestrales y comunitarios (Ação Grio), agentes de lectura y de cultura viva, premios a las mejores prácticas, escuela viva, cultura y salud, 'puntitos' de cultura con acciones para niños" (Brizuela \& Cabral Melo, 2021).

¿Qué le sucedió a este Sistema Nacional de Cultura en 2020 y 2021, desalentado por la indiferencia del gobierno federal, sus ataques y los de potentes movimientos religiosos de derecha que disputan el territorio y la organización simbólica y práctica de la vida social?

Un movimiento de miles de artistas, técnicos, activistas culturales e investigadores, reunidos en videoconferencias, promovió entre marzo y junio de 2020 una ley que destinó tres billones de reales (unos 600 millones de dólares) para trabajadores de la cultura, subsidios para mantener espacios artísticos y culturales, convocatorias públicas y premios. La Ley Aldir Blanc estableció que esos recursos fueran entregados a los municipios con la condición de que contaran con consejos locales de cultura. La acción en medios virtuales de los participantes produjo redes de solidaridad, reflexión y acción colectiva, cabildeo con legisladores que aprobaron mayoritariamente la Ley, intercambio de información y control ciudadano del uso y distribución de fondos. La articulación de redes horizontales movilizó las inercias de los aparatos partidarios. De los 5,570 municipios brasileños apenas $32 \%$ tenían estructuras y consejos locales capaces de recibir los apoyos, pero la movilización y el logro de recursos impulsó que la mayoría creara formas democráticas de gestión. Este proceso abarcó y puso a interactuar Puntos de Cultura que funcionan en centros tradicionales y modernos, iglesias y terreiros de candomblé (Cabral Melo, 2021).

¿Qué alcance puede tener este sincretismo intercultural que enlaza lugares de matriz indígena y afro, religiosos "modernos", interactuando con tecnologías y formas tradicionales de asociación local? Tanto la academia como las culturas populares brasileñas han respondido valorando estas combinaciones, escribió hace pocos años Roberto Schwarz. Recordaba las clases de Antonio Candido en las que incluía textos de formalistas rusos, Literatura y revolución de Trotsky, el estructuralismo y a Adorno: animaba a los estudiantes a experimentar con diversas teorías con la premisa de que toda aproximación más o menos consistente captaba algo de su objeto y por tanto no había que descartarla. Una posición antidogmática semejante a la de Riobaldo, el protagonista de Grande Sertão: veredas de Guimarães Rosa, que aprobaba todas las religiones siempre que le ayudaran a uno a vivir. Schwarz comparaba la ironía y el escepticismo, contrario a las pretensiones absolutistas de cada una de ellas tomadas por separado, con la irreverencia de Borges. En su ensayo "El escritor argentino y la tradición" sostuvo que la falta de grandes tradiciones nacionales llevaba a los escritores latinoamericanos a apoyarse en linajes externos y diversos: en una situación análoga a los judíos y los irlandeses, "podemos manejar todos los temas europeos, manejarlos sin supersticiones, con una irreverencia que puede tener, y ya tiene, consecuencias afortunadas". Colocaba en la misma línea la observación del crítico de cine brasileño Paulo Emilio Salles referida a "nuestra creativa incapacidad para copiar". Según Schwarz, debido a "que no tenemos una tradición propia, imitamos, pero como no sabemos cómo imitar bien, el resultado es otra cosa, una diferencia involuntaria que, sin embargo, es creativa, innovadora a su manera" (Schwarz, 2017, 56-57). 
Me acuerdo de una cena que tuvimos en un restaurante cerca del departamento de Renato Ortiz en Sao Paulo, en Higienópolis. Los que atendían las mesas estaban conversando muy divertidos en un extremo, cerca de nosotros. Yo trataba de hablar de la política brasileña, de la mexicana, de otros aspectos desdichados del mundo. Renato nunca fue partidario de las visiones apocalípticas, detenerse en las desgracias de la política. Era grande el contraste de lo que nosotros conversábamos sobre distintas catástrofes nacionales e internacionales y lo que sucedía con ese grupito de uniformados para atendernos en el restaurante, sumamente divertidos. Le pregunto a Renato - ¿Por qué están tan felices? Responde - Son paganos.

\section{Congresos: ¿en cuántos minutos se puede aprender a ser intercultural?}

Este camino para repensar la cultura y la ciudadanía en una época transnacional es desafiado, sin embargo, cuando llegamos a las mutaciones de la sociedad brasileña y de otras latinoamericanas en los últimos años. La interculturalidad politeísta, que parece un recurso atractivo para fundar políticas de coexistencia ciudadana plural, se vuelve problemática al llegar, en tantos países, al exasperado fundamentalismo reciente. El autoritarismo y la militarización, legitimados por vías electorales, plantea problemas inéditos a la sobrevivencia democrática y a la convivencia intercultural.

¿Cómo explicar la transmutación de las culturas urbanas y de otras capas populares, que apoyaron a partidos progresistas en periodos anteriores y ahora aprueban políticas económicas que los despojan? La investigación de la periodista francomarroquí Lamia Oualalou propuso otras claves al estudiar cómo los evangélicos se arraigaron en las áreas más pobres de Brasil, mientras la Iglesia Católica y la izquierda se alejaban de esos sectores concentrándose en las zonas urbanas. El avance evangélico, dijo en una entrevista, tiene dos explicaciones socioculturales y comunicacionales: la capacidad de los pentecostales y otras Iglesias no tradicionales de dar acogida, sociabilidad y protección a los marginados, y la de crear medios de comunicación que los representen. El Estado estuvo casi ausente en las favelas y zonas marginales al mismo tiempo que la economía neoliberal producía más precariedad. "Cuando le preguntaba a la gente por qué iba a la Iglesia evangélica, el argumento teológico no aparecía. En el templo evangélico pueden cantar, hacerse de amigos, dejar a sus hijos. No están presentes ni el Estado con políticas públicas (salud, trabajo, educación), ni la Iglesia católica, pero sí están presentes los evangélicos que prestan algunos de esos servicios". En los templos encuentran un lugar de respaldo. "Si alguien pierde su trabajo, la red se activa hasta que consigue uno. Y si le hace falta comida le dan arroz. Los evangélicos, en Brasil, ocuparon el espacio del Estado con el consiguiente impacto cultural y político que ello acarrea. La gente vive encerrada en ese mundo, todo el tiempo. Y esto pasa en parte también porque los movimientos progresistas, los partidos de izquierda, abandonaron a esta gente con un nivel de prejuicio muy alto. No hay que olvidar que el PT está muy ligado con la izquierda católica” (Febbro, 2018).

Este giro de la mirada desde los vínculos con instituciones religiosas, partidos y sindicatos hacia las expectativas y las nuevas vías de socialización amplía las preguntas sobre cómo se forman ciudadanos. En países como México y los centroamericanos, a la expansión evangélica se agregan los empleos ilegales y los "servicios sociales" proporcionados por las mafias que operan donde los organismos públicos se desentienden de las necesidades.

¿Cómo está cambiando la antropología para hacerse cargo de estas mutaciones e incertidumbres? Desde fines del siglo pasado se multiplican los intercambios y encuentros internacionales, especialmente latinoamericanos, que expanden el horizonte de las antropologías "nacionales". El V Congreso de la Asociación Latinoamericana de Antropología y XVI Congreso de Antropología en Colombia, celebrado en julio de 2017, señaló la necesidad de internacionalizar los programas y los estudios comparativos en vista de retos generalizados: 
"cambios sustanciales en políticas de ciencia y tecnología", "modificaciones en las perspectivas laborales e imaginarios sociales de la disciplina que, articuladas a transformaciones generacionales, explican modificaciones en la agenda y prioridades en la labor antropológica".

El crecimiento de estudios comparativos y la confrontación con presupuestos de las antropologías de países coloniales fueron estimulando estudios y debates geopolíticos sobre la producción de conocimiento y las zonas sociales de acción. "Descolonización”, "antropologías del sur", son algunas de las posiciones desde las cuales se ensaya replantear el campo intercultural de la disciplina y comprender la complejidad de las sociedades, los vínculos con los Estados, las fuerzas partidarias y los movimientos y organizaciones societarias. Temas clásicos de la investigación, como el racismo, la xenofobia y las migraciones y desplazamientos se reelaboran en nuevos registros como los discursos y las prácticas de odio, los derechos humanos, el feminismo, las performances, corporalidades y emociones. Otros ejes de acción social de los antropólogos, iniciados desde los años 70 u 80 del siglo pasado, digamos el patrimonio, los museos y las políticas culturales, se rediseñan ante la expansión transnacional de las problemáticas generada por el turismo, los medios masivos y las redes sociodigitales. Las fronteras y continuidades entre lo humano y lo no humano desestabilizan en la era del Antropoceno lo que la antropología venía sosteniendo, revelan la urgencia de investigar colaborativamente, a escala global y regional, las peripecias actuales de la interculturalidad. Cómo hacer etnografía y reconceptualización teórica desde una sociedad hacia -y con- otras distintas hace tiempo dejó de ser la experiencia ocasional de extrañamiento de los occidentales, se volvió la condición habitual de la práctica en la disciplina. Las dudas anteriores al confinamiento pandémico se acentuaron a partir de 2020 y exigen replantear viejas certezas y "soluciones".

Los grupos de trabajo internacionales se han vuelto uno de los recursos para institucionalizar esta búsqueda. Se ha sugerido que podrían ocupar en los congresos el lugar de las conferencias magistrales. $O$ de las mesas redondas en las que cada uno, luego de viajar 8 a 15 horas, puede hablar 10 minutos, leer unas cuartillas o improvisarlas, sin que quede tiempo para confrontar en serio lo que converge o discrepa. Hay intereses de las pirámides de prestigio y de la organización empresarial de congresos multitudinarios que dificultan la transición a nuevos procedimientos. La distancia acentuada por las participaciones virtuales en estas escenas a veces habilita experiencias imaginativas y fecundas, en otros casos teatralizan torpemente esos ciberterritorios que tanto nos cuesta comprender.

Un lugar para avizorar lo que viene se encuentra en las nuevas generaciones de estudiantes que se abren fluidamente a los desafíos de lo trasnacional, a los aportes y retos de las tecnologías digitales, en las experiencias de posgrado y trabajo de campo en países distintos al propio. Me limito a sugerir algo a partir de nuestra experiencia en el Posgrado en Ciencias Antropológicas de la Universidad Autónoma Metropolitana de México.

Desde su creación, en 1993, hemos tenido 77 estudiantes extranjeros de 15 países, la mayoría de América Latina (destacan Chile con 10, Colombia con 9, España con 7, Argentina y Guatemala con 6 cada uno. Tres alumnos vinieron de Japón y otros tres de Italia). Varios trabajaron temas mexicanos, muchos de sus naciones de origen. Sus intereses abarcan desde cuestiones indígenas o patrimoniales hasta el papel de los medios y redes en la construcción de ciudadanía, las migraciones internacionales, el turismo alternativo, los museos en relación con comunidades transnacionales, las rebeldías virtuales, la pertenencia a la nación y a mercados fuera de Brasil de maracatús pernambucanos.

Dos testimonios de estudiantes brasileñas. Ana Laura Gamboggi, cuya tesis se tituló Lo que no se puedellevar en la maleta (se ocupó del museo armado por desplazados a causa de una represa en el nordeste brasileño), dijo -al preguntarle sobre la diferencia entre estudiar y ser antropóloga en Brasil y en México: “ A pesar de ser reconocida internacionalmente la Antropología Mexicana en Brasil no se conoce mucho, creo que la antropología brasileña todavía se relaciona muy poco con la antropología de América Latina, y menos aún con la Mexicana. 
Creo que eso se debe en parte por la cuestión del idioma y en parte porque ambos lugares producen una literatura antropológica de sí para sí mismas. Si bien trabajan temas comunes, especialmente en lo que son las cuestiones indígenas, migratorias, de problemas urbanos y de medio ambiente".

Renata Rocha, graduada en comunicación en la Universidad Federal de Bahía, se formó también en varios programas comunitarios con moradores en barrios periféricos, indígenas y el movimiento de trabajadores sin tierra, así como en centros de estudios multidisciplinares. También un año en España, donde "em uma conversa com amigos europeus, ao ouvir 'vocês, latino-americanos', refutei a caracterização, afirmando que eu era brasileira. Imediatamente percebi a gafe e tentei me corrigir afirmando que tinha interpretado 'vocês, hispanoamericanos'. Foi a partir desse momento que me dei conta do profundo abismo entre os brasileiros e os demais países da América Latina, quanto à nossa auto identificação a essa região". De octubre de 2012 a enero de 2013 obtuvo una beca en el Programa de Doutorado Sanduíche no Exterior y eligió el Posgrado de la UAM en México. Dice que "a experiência de uma relação mais próxima e, de certa forma, mais horizontalizada, em comparação com as relações estabelecidas entre bolsistas brasileiros e seus orientadores em países da Europa e da América anglo-saxônica, também me permitiu estabelecer laços de cooperação mais sólidos”.

"Associada também a esse contexto mais geral, a realização de estudos de pós-graduação no México contribuiu para consolidar perspectivas que as experiências assinalada já indicavam: a compreensão de a América Latina - este espaço heterogêneo que ultrapassa, inclusive as delimitações geográficas, com toda sua complexidade e diversidade - encontra uma infinidade de semelhanças e conexões no que diz respeito aos seus processos históricos, políticos, culturais e sociais".

Tal vez las pistas para imaginar el futuro de las antropologías en sociedades que somos cada vez más interculturales, y con tantos tropiezos para querer serlo, están en estos congresos, grupos de trabajo transnacionales y estudiantes que eligen vivir "sándwich", Por supuesto, también encaminando los modos más abiertos de producir el saber antropológico, a las prácticas globalizadas de la interculturalidad. No solo en las organizaciones que promueven el pluralismo democrático, la comprensión y los derechos, como las ONG, sino donde discrepamos y se excita el multiculturalismo agresivo o los fundamentalismos de derecha. Lo están haciendo, por citar un ejemplo, los antropólogos forenses que buscan desaparecidos, investigan restos, con familiares y comunidades: una de las formas más radicales de trabajar con la identidad. Lo hacen en las fronteras interdisciplinarias, con arqueólogos, expertos en computación, patólogos, radiólogos y juristas. También donde se cruzan autoridades locales, nacionales, mafias y organismos de derechos humanos internacionalizados. Es solo un ejemplo de cómo reubicar la disciplina, la labor científica, en los desencuentros entre sociedades sin confianza, políticos desacreditados y sistemas de justicia. Crear convivencia en las escalas en que hoy se duda que sea posible.

Recibido: 20 de julio de 2021

Aprobado: 05 de agosto de 2021 


\section{Bibliografía}

ABELES, M. 1996. En attente d'Europe : Débat avec Jean-Louis Bourlanges. Paris : Hachette Litterature. ABELES, M. 2011. Des anthropologues à l'OMC. Scènes de la gouvernance mondiale. Paris : CNRS Editions. BRIZUELA, J. I. \& CABRAL MELO, S. M. 2021. "Instituições em emergência cultural: da Cultura Viva Comunitária à Lei Aldir Blanc”. En: Cadernos de Pesquisa da Cátedra Olavo Setubal de Arte, Cultura e Ciência. A institucionalidade da cultura e as mudanças socioculturais, 1: 43-53. São Paulo : Editora Amavisse.

CABRAL MELO, S. M. 2021. "A enérgica e larga melodia do acontecimento: relatos sobre a lei Aldir Blanc". En: Cadernos de Pesquisa da Cátedra Olavo Setubal de Arte, Cultura e Ciência. Emergências Culturais LatinoAmericanas: Das Histórias aos Acontecimentos no Brasil. 2: 12-43. São Paulo: Editora Amavisse. En Prensa

DA MATTA, Roberto. 1980. "Você sabe com quem está falando?: um ensaio sobre a distinção entre individuo e pessoa no Brasil”. En: Carnavais, malandros e heróis. Rio de Janeiro: Zahar.

FEBBRO, E. 2018. “¿Por qué crece el evangelismo en Brasil y qué consecuencias políticas tiene? Entrevista con Lamia Oualalou”. Nueva Sociedad, octubre. https:|/nuso.org/articulo/por-que-crece-el-evangelismoen-brasil-y-que-consecuencias-politicas-tiene/

FEIXA, C. 2014. De la generación@ a la \#generación. La juventud en la era digital. Barcelona: Ned Ediciones. GARCÍA CANCLINI, N. 2001. La globalización imaginada. México: Editorial Paidós Mexicana.

GARCÍA CANCLINI, N. 2018a. "La conversación y la risa”. En: La interculturalidad y sus imaginarios: Conversaciones con Néstor García Canclini Barcelona: Editorial Gedisa. $1^{\mathrm{a}}$ edición, pp. 362-372.

GARCÍA CANCLINI, N. 2018b. "La cultura internacional-popular en el siglo XXI", Ciências Sociais Unisinos, 54(2): pp.161-166.

LINS RIBEIRO, G. 2008. Postimperialismo: cultura y política en el mundo contemporáneo. Barcelona: Gedisa.

LOMNITZ, C. 1992. “Usage politique de l’ambigüité : le cas mexicain”. L’Homme, 32(1): 99-121.

O’DONNELL, G. 1984. ¿Y a mí, qué me importa?: notas sobre sociabilidad y política en Argentina y Brasil. Buenos Aires: CEDES.

ORTIZ, R. 1988. A moderna tradição brasileira. São Paulo: Editora Brasiliense.

ORTIZ, R. 1997. Mundialización y cultura. Buenos Aires: Alianza Editorial.

REGUILLO, R. 2017. Paisajes insurrectos: Jóvenes, redes y revueltas en el otoño civilizatorio. España, Barcelona: Ned Ediciones.

SCHWARZ, R. 2017. “Antonio Candido, 1918-2017". New Left Review, 107: 51-59.

\section{Néstor García Canclini}

Universidad Autónoma Metropolitana

Investigador Emérito del Sistema Nacional de Investigadores de México

https://orcid.org/0000-0002-5777-8230

E-mail:drngc197@hotmail.com 